\title{
Oxygen Conservation Strategies in Hospital- Current Perspectives
}

\author{
Dr. Nikhil Mudgalkar*
}

\section{*Professor of Anaesthesia,Prathima Institue of Medical Sciences,Nagnur Road,Karimnagar}

Corresponding author: Dr. Nikhil Mudgalkar, Department of Anesthesia, Prathima Institue of Medical Sciences, Nagnur Road,Karimnagar

\section{drniks2000@yahoo.com}

DOI: 10.47799/pimr.0901.01

Received: 6/5/2021

\section{Accepted: 7/5/2021}

The significance of oxygen has never been more apparent. The Covid pandemic has swept the globe like never before, and the need for oxygen in hospitals and intensive care units has skyrocketed. The oxygen supply cannot be raised overnight, but the corona virus is quickly spreading, causing a supply and demand mismatch. Until the availability of oxygen is increased, judicious use of oxygen is needed, and oxygen conservation strategies must be strictly followed. Many societies, such as the Indian Society of Anaesthesia, have stepped forward in these trying times and published widely read advisories ${ }^{1}$. It is important to follow these notifications in order to conserve oxygen.

Anaesthesia can only be used for life-threatening or semi-life-threatening operations. All elective procedures should be delayed until the next available date in order to divert more oxygen to covid patients. Elective patients should be advised that covid is a transient occurrence, and that once it is under control, elective surgery may be scheduled. This also means a larger population of anaesthetists is diverted towards covid care.

The understanding of a hospital's oxygen distribution system and related contingency measures for internal emergency management is governed by anaesthetic and critical care personnel. In the event of a central oxygen pipeline failure, they should be well-prepared and adequately equipped to facilitate an institution-wide emergency response.

Maintenance of medical gas pipeline systems should be coordinated and registered by all parties concerned. The gas company and the hospital engineering team must flush the tubing, check the pressures, and analyse and certify the gas after maintenance or modifications to a medical gas pipeline system.

In the event of an oxygen shortage, the AMBU bag must be readily available, and oxygen analyzers are an effective tool for assessing the overall oxygen situation.

For emergency surgery, we must use regional anaesthesia procedures wherever possible. For general anaesthesia for emergency surgery, we must use low flow anaesthesia. We must use oxygen sparingly in the postoperative phase.

An anesthesiologist is qualified to determine whether or not a patient requires oxygen treatment. In this covid situation, a target oxygen saturation of 94 is a reasonable guide. Also, this should not be the only criterion used; when deciding on a target, it is necessary to consider the patient's overall situation.

Reservoir cannulas and demand oxygen delivery systems are examples of oxygen-saving devices ${ }^{2}$. They're made to prolong the life of portable oxygen cylinders while also correcting hypoxemia with a lower oxygen flow rate. At the start of the inspiratory process, reservoir cannulas increase the fraction of oxygen that is inspired. Demand oxygen delivery systems have a valve that is triggered during inhalation, ensuring that oxygen is only supplied during this stage of the respiratory cycle.

To summarise, oxygen is extremely valuable in these unpredictable times. Every effort should be made to preserve it. To maximise the patient's outcome, proper monitoring must be maintained.

\section{REFERENCES}

1. Indian Socity of Anesthesiology. Advisory From Indian Society of Anesthesiologist( National) [Internet]. isaweb.in. 2021 [cited 2021 May 6]. Available from: https:/ / i s a w e b. i n / A t t a c h m e n t / ADVISORY\%20ISA\%20NATIONAL\%2026\%20APRIL\%202021.pdf

2. Castillo D, Güell R, Casan P. Oxygen-Conserving Systems: A Forgotten Resource. Archivos de Bronconeumología ((English Edition)) [Internet]. Elsevier BV; 2007 Jan;43(1):40-5. Available from: http://dx.doi.org/10.1016/ s1579-2129(07)60019-6

How to cite this article : Mudgalkar N .Oxygen Conservation Strategies in Hospital- Current Perspectives. Perspectives in Medical Research 2021; 9 (1):1

DOI: 10.47799/pimr.0901.01

Sources of Support: Nil, Conflict of interest: None declared 